\title{
"Clothes" The Loop: Raising Awareness of Sustainable Fashion Among Millennial Consumers Through Digital Platforms
}

Nell Gray Rasmussen 


\section{Introduction}

Historically, humans have been consumers rather than replenishers of raw materials and natural resources (Mason, n.d.). The late $20^{\text {th }}$ century was the turning point for noticeable climate change and greenhouse effects resulting from a multitude of industries' unsustainable practices. In the $21^{\text {st }}$ century, movement towards renewable sources and eco-friendly practices continues to evolve due to greater awareness of the depletion of resources, pollution, and rising threats to health and ethical practices.

The fashion industry consists of a complex supply chain that includes mills, manufacturers, retailers and ecommerce, auxiliary support businesses, and end-consumers. In order to maintain a sustainable future, every aspect of this supply chain needs to improve.

The adverse effects within the supply chain and substantial increases in consumption levels have led to the sustainability movement. A study from the University of Queensland found consumers are buying $400 \%$ more clothing than the amount consumed two decades earlier ("Fast Fashion," 2018). This trend of overconsumption is a principal issue, along with consumers' lack of awareness regarding sustainable options and industry improvements.

Knowledge and use of sustainable practices within the fashion industry is slowly increasing as brands begin to implement strategies for improvement of sustainable practices and consumers gain awareness of the detrimental effects their clothing may have on people, society, and the environment.

\section{Purpose of the Study}

The fashion industry is becoming increasingly committed to sustainable practices. Progressive responsibility by industry professionals is driving this momentum for change. The purpose of this study is to research sustainable practices within the fashion industry. Additionally, a mobile application prototype featuring sustainable brands will be created. This mobile application will be characterized by a rating system to influence Millennial consumers to buy sustainable clothing. Millennials will gain awareness of sustainable fashion brands through specific social media marketing and the availability of information regarding sustainability within the mobile application.

\section{Statement of the Problem}

The average consumer is not aware of the consequences of the cost of cheap clothing and overconsumption. Educating today's Millennial consumer about the importance and benefits of sustainable clothing consumption is of utmost importance. Objectives for this study include (1) defining the importance of sustainability within the fashion industry, (2) identifying the Millennial consumer and synthesizing communication outlets most effective for information accumulation, and (3) producing a mobile application to inform and encourage sustainable purchases. 


\section{Rationale for the Study}

Clothing is a vital component of everyday life for people around the world. The motivation for this study is to raise awareness of the importance of sustainability through the development of a mobile application prototype targeted towards Millennial fashion consumers in an effort to encourage sustainable consumption. In order for significant change to happen, the consumer must first understand the importance and benefits of sustainable practices and commit to responsible clothing purchases. Sustainable consumption focuses on buying longer-lasting slow fashion items provided by ethical brands. According to Sabell (2016), "the consumer is the key figure in the supply chain, and their needs and opinions will affect the supplier's decisions" (para. 2). This study is critical because customers are conditioned to overconsume as a result of the accessibility of inexpensive fast fashion and serial sales. Today's average consumer contributes to the linear economy due to their lack of awareness of sustainable options and lack of knowledge regarding the true cost impact of their purchasing decisions. This study will educate Millennial consumers about the power of sustainability through the development of an ecommerce mobile application prototype. This prototype will motivate them to make purchasing decisions that protect the environment for future generations and support a circular economy.

\section{Study Questions}

Research questions for the study include the following:

1. How does the fashion industry define sustainability?

2. What are the sustainable initiatives that provide a basis for sustainable practices?

3. What is a linear economy in comparison to a circular economy?

4. How has fast fashion altered the industry and consumption patterns?

5. What characteristics define today's Millennial generation and their use of digital media?

6. What is the role of Millennial consumers in the movement towards sustainable practices?

7. What is the best method to encourage sustainable consumption and educate the importance of sustainability?

\section{Limitations}

The limitations of the study include the following:

1. Analysis of sustainable practices within the apparel industry

2. Evaluation of the impact of sustainable practices on environmental and economy

3. Assessment of specific apparel industry initiatives

4. Specific focus on the Millennial generation

5. Assessment of Millennial apparel consumption patterns

6. Development of iPhone IOS mobile application prototype

7. Assessment of ten sustainable brands 


\section{Definitions}

The definitions for the study, as they pertain to this research, include the following:

1. Consumerism - the social and economic purpose of today's consumer to continually shop and purchase apparel items.

2. End User - the person who uses an apparel product. The end of the supply chain associated with a linear economy.

3. Millennials - the generation of individuals born between 1981-1996.

4. Overconsumption - the act of consumers purchasing apparel items in excessive amounts, typically motivated by fast fashion trends.

5. Rating System - the system used to distinguish specified fashion brands as sustainable or unsustainable based on three specific attributes 1) brand's ability to close the loop, 2) positive environmental actions, and 3) support of sustainable efforts towards industry research and sustainable initiatives.

6. Sustainable Brand - apparel brands providing sustainable clothing options that meet the specific requirements defined within the rating system.

\section{Review of Literature}

The literature review explains several aspects of sustainability in today's fashion industry. Topics addressed in the review of literature include 1) sustainability in the apparel industry, 2) the linear versus circular economy models, and 3) the Millennial consumers and their digital media consumption patterns.

\section{Definition of Sustainability}

The apparel industry is a complicated business that has caused the world both environmental and social exhaustion. Sustainable fashion movements consist of environmental, economic, and social practices to maintain natural resources and safe labor environments while gaining a more significant profit margin. The concept of sustainable fashion has become an issue for industry professionals, including designers, manufacturers, and brands. The fashion industry possesses a range of sustainability goals, universal assessment, and resources for sustainability knowledge to inspire and educate apparel companies to make drastic changes. The Council of Fashion Designers of America, Inc. (CFDA) is dedicated to sustainable practices as a pioneer within the industry. The CFDA's goal is to educate and assist industry professionals and brands to commit to sustainable business models and ethical practices. The CFDA's general definition of sustainability is great design. [Sustainability] is based on a deep understanding that all things are interconnected in this world. Sustainability provides the ability to design and produce indefinitely. [Sustainability] requires that the design, development, production, and use of 
fashion products meets today's needs without preventing them from being met by future generations (Leibowitz, 2019, p.13).

The fashion industry is currently unsustainable, but productive changes made by industry leaders' initiatives are beginning to impact positive business and consumer decisions.

\section{Sustainability Practices}

The CFDA provides industry professionals with a Guide to Sustainable Strategies. This sustainability model explains universal common goals, a comprehensive metric system, and global associations to assert and perpetuate new sustainable measures for the industry. This sustainability handbook is available to the public and useful for educating industry professionals as well as consumers. The CFDA's Guide to Sustainable Strategies provides industry initiatives and research-based information as resources for industry professionals to increase and maintain sustainable practices. The United Nations defines the global consensus for sustainable practices through the United Nations' " 17 Sustainable Development Goals" (see Appendix A). A total of 193 countries support these goals to promote prosperity while preserving the environment. Overall, the seventeen goals culminate in the mission to terminate poverty and enhance economic growth through social strategies of education, health, and jobs, while also supporting the environment (Leibowitz, 2019). The United Nations aims to achieve these goals by 2030, exemplifying the support of national governments towards positive change for all global citizens.

The Sustainable Apparel Coalition (SAC) is the leading association for the sustainable production of the apparel, footwear, and textile industries. The SAC developed the Higg Index, which is the universal "suite of tools. ... to measure and score a company or product's sustainability performance" (Leibowitz, 2019, p. 17). The Higg Index strives to provide a standard metric variable across all fashion companies to easily compare brands based on their sustainability efforts.

The final element of CFDA's leading sustainable associations includes The Global Fashion Agenda (GFA). The GFA consists of four initiatives: The Copenhagen Fashion Summit, The CEO Agenda, Pulse of the Fashion Industry Report, and the Circular Fashion System Commitment. Together, these associations provide leadership in sustainable fashion. As a whole, the GFA focuses on communicating the necessary knowledge for industry professionals to implement sustainable methodology (Leibowitz, 2019). The Guide to Sustainable Strategies provides specific guidelines that companies can implement within their brands to improve their sustainable efforts and practices.

\section{Fast Fashion}

The emphasis on sustainable practices in recent years has resulted in the rise of "fast fashion" consumption. Fast fashion refers to low-cost, poor-quality garments produced in an expedited timeframe, alongside quick turnover of fashion trends, to maximize company and store profits. Fast production, fast sale, and fast use explains the short life span of fast fashion apparel items from production, to retail, to the end consumer. The rise of fast fashion has evolved and changed the 
way clothing is manufactured and sold through a system of low-quality production and low-cost consumption. Elizabeth L. Cline (2012), author of Overdressed: The Shockingly High Cost of Cheap Fashion, states,

the fashion industry is designed to make you feel "out of trend" after one week. Once upon a time, there were two fashion seasons: Spring /Summer and Fall/Winter. Fast forward to 2014, and the fashion industry is churning out 52 "micro-seasons" per year. With new trends coming out every week, the goal of fast fashion is for consumers to buy as many garments as possible, as quickly as possible (p. 119).

The rapid production of clothing has resulted in overconsumption of goods by consumers, which leads to global, environmental, and ethical issues. Environmental problems include textile waste, depletion of non-renewable sources, rise in greenhouse gas emissions, and massive increase in energy, chemical, and water use, particularly in developing countries. Ethical problems include forced child labor, poor working conditions, lack of fair trade, and worker exploitation ("Fast Fashion," 2018). The fashion industry is making slow progress towards sustainability through necessary interventions within the supply chain and the increase of slow fashion.

\section{Slow Fashion}

Slow fashion is influencing today's textile complex and continues to evolve as the sustainable fashion movement increases. Kate Fletcher (2007), a fashion and sustainability pioneer, writer, and design activist, describes slow fashion as designing, producing, consuming and living better. Slow fashion is not time-based but qualitybased (which has some time components). Slow is not the opposite of fast - there is no dualism - but a different approach in which designers, buyers, retailers and consumers are more aware of the impacts of products on workers, communities and ecosystems.... Slow fashion is about choice, information, cultural diversity and identity. Yet, critically, it is also about balance. It requires a combination of rapid imaginative change and symbolic (fashion) expression as well as durability and long-term engaging, quality products (para. 5).

Slow fashion inspires designers, manufacturers, and retailers to design and produce apparel products using sustainable practices to direct industry supply chains away from fast fashion, which contributes to a linear economy. Fast fashion is low-quality, disposable goods, whereas slow fashion indicates garments made from higher quality fibers and durable fabrics, providing longer lasting products. Slow fashion focuses on quality over quantity, which encourages the consumer to make smarter purchasing decisions and limit over consumption. 


\section{Linear Economy versus Circular Economy}

Congresswoman Carolyn B. Maloney (2015) affirms the fashion industry as "a highly sophisticated, $\$ 2.5$ trillion global industry" (p. 1). This significant financial contribution to the global economy is exponential, but it "achieves the decoupling of economic growth from natural resource depletion and environmental degradation" (Hvass \& Pedersen, 2019, p. 345).

Fashion supports today's linear economy, which demonstrates the "take - make - dispose [method], that is, take the resources you need, make the goods to be sold and make profit, and dispose of everything not needed - even including a product at the end of its lifecycle" (Sariatli, 2017, p. 32). The Ellen MacArthur Foundation, which supports the positive structure of a circular economy, explains that the linear ideology is based on $20^{\text {th }}$ century ideals when an abundance of material, technologic advances of production, and the desire for profits generated business success ("Towards a Circular Economy," 2015).

In the $21^{\text {st }}$ century, environmental damage is the primary concern due to textile waste from overconsumption. According to the United States Environmental Protection Agency's (EPA) 2017 waste report, the textile industry generated 16 million tons of textile waste of which

10.46 million tons were sent to landfills. Textile waste reflects $6.1 \%$ of total landfill waste in the United States. Of this total waste, $95 \%$ was recyclable (EPA, 2019). The average American consumer throws away approximately eighty pounds of clothing every year (EPA, 2019). The linear economy supports product disposal at the end of its lifecycle. Textile waste is a rising concern due to the increased amount of synthetic fibers being produced and used within the apparel industry. Synthetic fibers, specifically polyester, take at least two-hundred years to decompose, leaving today's waste for future generations to manage (EPA, 2019). John Hilary, the executive director for War on Want and a prominent activist against global poverty, inequality, and injustice, states in The True Cost movie:

There are very defined limits on how much the world can sustain in terms of production, in terms of trade, in terms of transport and distribution. It is quite clear we have overstepped those limits, which is why [there is] so much stress in the natural world at the moment (Morgan, 2015, 00:32:45).

These limits have drawn attention to using a circular production system in order to address the environmental impact of apparel manufacturing and overconsumption. This production system is used within the circular economy and is defined as the "circular or closed flow of materials which use raw materials and energy through activities that [reduce, reuse, and recycle] materials in [production, distribution, and consumption processes]" (Hvass \& Pedersen, 2019, p. 349). This model aims to ensure economic success, while also improving the environmental impact for future generations.

The circular economic movement is a positive trend for the fashion industry. In the Council of Fashion Designers of America's (CFDA) sustainability initiative, the circle economy "proposes a future where design is a positive, regenerative force, producing effects that we want to expand rather than shrink. In addition to having a positive impact, products create no waste - all materials are either infinitely recyclable or biodegradable" (Leibowitz, 2019, paras. 2-3). The movement towards a circular economy is necessary in order to become more sustainable. 


\section{Importance of Consumers}

The fashion industry possesses a range of sustainability goals, universal assessment, and resources for sustainability knowledge, and the CFDA acts as the bridge of sustainable communication to the industry. However, there is not a clear bridge of sustainable communication from analysts to consumers. All consumers play an essential role within the fashion industry as end users. According to an interview in The True Cost, fashion designer and luxury brand CEO Stella McCartney believes "the customer has to know that they are in charge. Without them, we do not have jobs. ... so if [the consumer] does not like it, [the consumer] does not have to buy into it" (Morgan, 2015, 01:05:22). Consumer decisions and purchasing power lead to brand and product success.

\section{Millennial Generation and Sustainable Fashion}

Interest in becoming a sustainable shopper is on the rise, particularly within the Millennial generation. Current research has shown significant intent among Millennials to buy sustainable clothing. However, these consumers seldom act on their intent because their awareness levels of eco-fashion brands are low, partially due to limitations in product availability, influential brand marketing strategies, and lack of readily available information (D’Souza, 2015). Millennials are "driving the demand for sustainable goods and services," (Baizley, 2018, p. 5) as both a consumer and investor. Research "found that Millennials are twice as likely as the overall investor population to invest in companies actively involved in good social and economic practices" (Stanley, 2017, p. 1). The Millennial generation is the target market for influencing positive change towards sustainable consumption.

\section{Profile of the Millennial Generation}

Millennials are not monolithic among their generation group, due to its large size. Born between 1981-1996, Millennials represent 25\% of the population in 2019 and hold a vast majority of spending power (Mander \& Trifonova, 2019). This generation contains consumers in varying life stages ranging from graduate students, working professionals, homeowners, and parents. Millennials are not a uniform consumer, which allows for the industry to capitalize on sustainable consumption as they reach prime working and spending years.

This generation grew up during the beginning of the information age and the launch of the internet and smartphone (Mander \& Trifonova, 2019). Millennials' "affinity for technology helps shape how they shop. They are used to instant access to price comparisons, product information and peer reviews" (Goldman Sachs, 2020, para. 1). Digital media allows Millennials to express their needs and opinions and stay connected throughout multiple mediums including daily news updates, text messaging, e-mail, and social media. 


\section{Social Media and Digital Marketing}

The linear economy encourages overconsumption and waste due to the make, take, and dispose method of use. Marketing strategies used by sustainable brands need to be revamped to communicate sustainable strategies clearly to consumers. Consumers today are motivated by low prices and the perception of value, which leads to overconsumption of products. Marketers have capitalized on this mindset, using advertisements as a form of propaganda to convince consumers that a product can make their lives better. Sustainability and corporate social responsibility expert Luna Atamian Hahn-Petersen (2018) states “the gap between [M]illennials' who stated interest in sustainability and their actual purchasing patterns is not due to lack of conviction but product availability and lack of clear marketing” (para. 1). Through marketing strategies and utilizing social media platforms, brands have the opportunity to reach Millennials and influence their purchasing decisions.

Social media is the second most important product research channel for millennials after search engines (Mander \& Trifonova, 2019, p. 3). Millennials utilize internet and social media outlets to interact, follow, and discover brands. In the 2019 Millennials Report, researchers explain that social media "is more about consumption than contribution" (Mander \& Trifonova, 2019, p. 26). Millennials utilize social media to follow and discover brands which leads to in-app purchases and profit for a company. Social media is a prominent marketing platform that can be used to expose consumers to sustainable fashion brands.

\section{Methodology}

This section describes the research procedures used for the protype of a sustainable ecommerce mobile application. A personalized digital experience targeted towards the Millennial consumer will be prototyped in an effort to educate and provide an accessible, simple source for sustainable consumption. The methodology is divided into two sections. The two sections explain the exact specifications that I used for the execution of deliverables. Research regarding the Millennial generation and sustainable consumption patterns was derived from existing data sources that were analyzed to influence the development of a sustainability brand service across a mobile app and social media marketing deliverables.

\section{Application's Digital Features}

The movement towards sustainability has gained significant following from industry professionals across the supply chain, providing encouragement for brands to engage in sustainable practices and apparel production. While sustainable apparel is becoming more readily available, the messaging to consumers is limited at best. Therefore, many consumers continue to purchase unsustainable products. 
The development of a digital sustainability database and ecommerce experience will provide Millennial consumers with the relevant industry research to better inform their purchasing decisions. Mobile applications are prototyped and developed for a specific purpose or action, which ultimately assist users in completing a desired action. Through this digital app, Millennial consumers can search fashion brands, learn about their sustainable practices, and see each brand's level of sustainability through a consumer-friendly rating system. The rating system will be based on available industry data that includes 1) circular product (an apparel item that can be repaired, recycled, reused, or repurposed); 2) materials (impact on environmental and natural resources i.e. fiber type, finish, dyes, pesticides); and 3) support of sustainable efforts towards industry research and sustainable initiatives. Industry-specific sustainable classifications will be used to determine the three specific ratings based on environmental, economic, and consumption effects.

\section{Digital and Marketing Platforms targeted for the Millennial Generation}

The development of a social media presence and marketing campaign will appeal to Millennials' desire to access information on clothing sustainability. A marketing campaign will provide simple, consistent advertisements to attract environmentally conscious Millennial consumers to the mobile app and encourage downloads and app use. Instagram is the social media platform used for advertising, due to the application's fashion prominence and personalized marketing. Instagram's algorithm allows for advertisements in users feeds. Advertising on Instagram is simple, customizable to specific user interests and recent searches, and less saturated than other social media platforms.

\section{Results}

Millennials have voiced their desire to purchase sustainable apparel products in an easy and accessible way. The development of the Loop logo utilizes consistent branding through the simplistic design and color (see Figure 1). I developed a prototype iOS mobile application called Loop, with several screens. Loop provides sustainability knowledge and encourages conscious consumption through the application's user profile, brand directory, and a sustainability news journal. The prototype of an iPhone mobile application is exemplified through visual mockup screen deliverables. Loop requires a log-in page and personal profile within the application in order to provide an individual app and shopping experience (see Figure 2). Loop creates a personal user experience through gamified features. By purchasing sustainable brands through the application, users will gain rewards and obtain a higher status within the app to encourage use and sustainable purchases. This reward system is visualized within the user's personal profile, along with individual suggestions and recommendations configured through the user's historical purchases (see Figure 9). 
Loop serves as a database for sustainable information and allows users to make a general search throughout the entire application (see Figure 4). The Loop brand directory contains a variety of apparel brands with a clear sustainability rating. The brand directory is categorized by apparel product or brand search optimization (see Figure 5). Loop contains specific brand search screens with information specific to the brand, including the optimized rating given to their sustainable practices (See Figure 6). This brand rating will be based on industry research and will provide users with comprehensible information in a simplified visual experience. The Loop rating system of sustainability will be based on available industry data that includes 1) circular product (an apparel item that can be repaired, recycled, reused, or repurposed); 2) materials (impact on environmental and natural resources i.e. fiber type, finish, dyes, pesticides); and 3) support of sustainable efforts towards industry research and sustainable initiatives. Industry specific sustainable classifications will be used to determine the three specific ratings based on environmental, economic, and sustainability efforts. The rating system is color coded to provide a clear visual representation of the brands within the Loop database. This color distinction includes green, yellow, and red, where green represents a brand with successful implementation of sustainability, yellow represents semi-successful implementation of sustainability, and red represents a brand with poor or no sustainable implementation of sustainability. (see Figure 7).

The sustainable news journal will continue to focus on social, in-app experiences through updated sustainability news and blog posts to keep users informed and encourage continual sustainable research and knowledge (see Figure 8). Social media will provide an outlet for more users to discover Loop. The Instagram advertisement is developed to influence users to download Loop. Social media marketing will assist in quantifying the number of users and spreading the word of Loop's effort to provide sustainability research in an accessible way.

Figure 1: Loop Logo Opening Screen

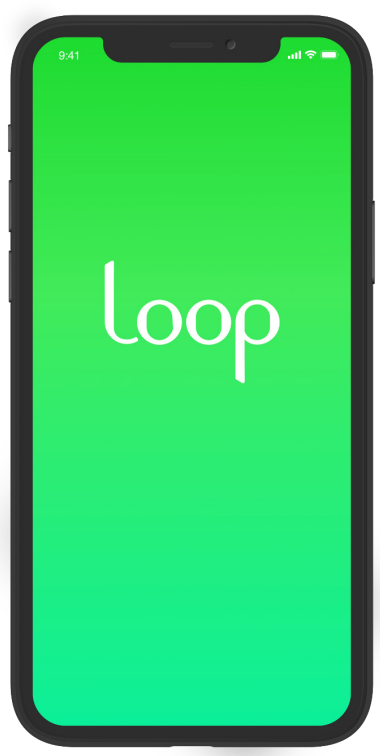

Figure 2: Login Page

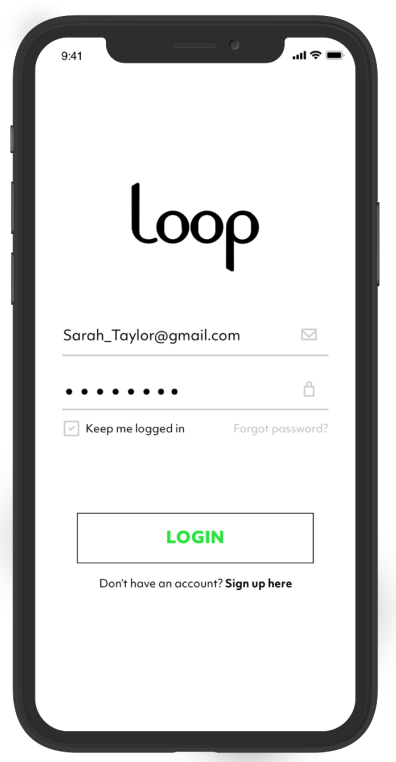


Figure 3: Loop Home Screen

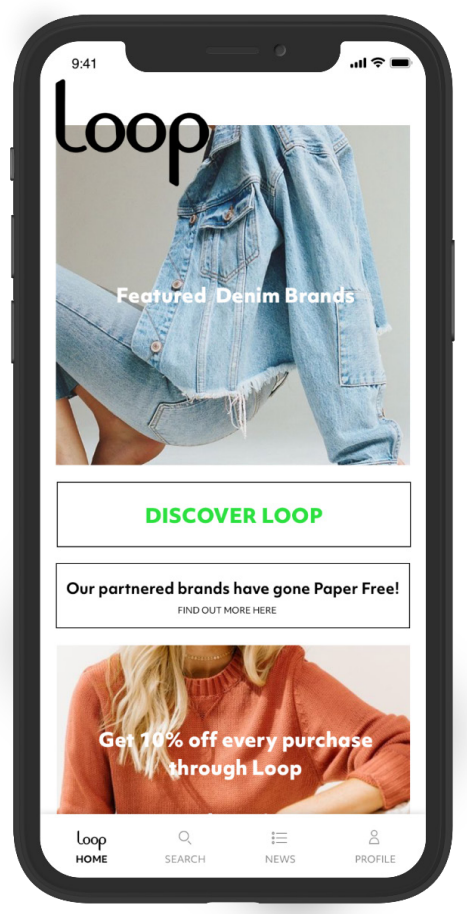

Figure 5: Brand Directory Search Screen

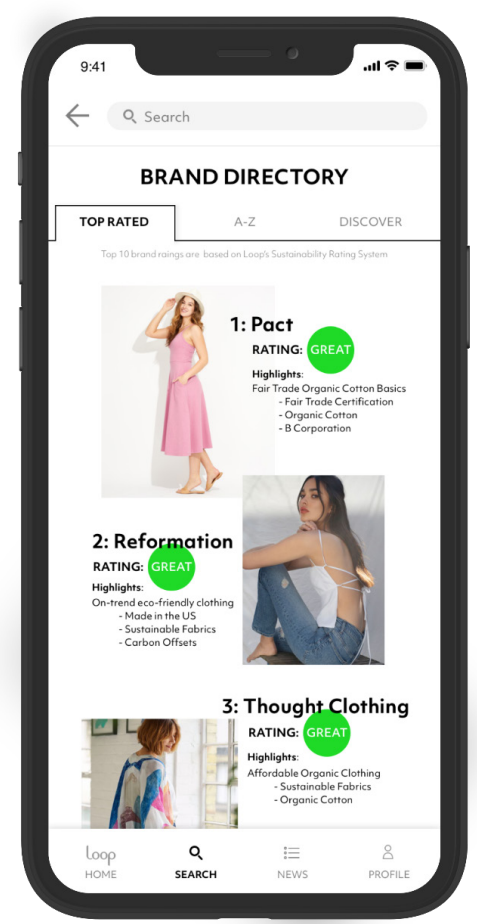

Figure 4: General Search Screen

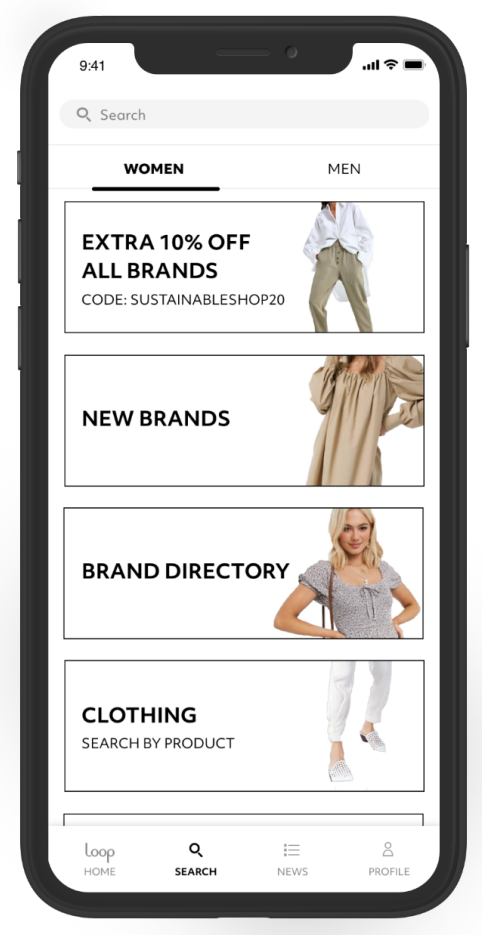

Figure 6: Brand Landing Screen

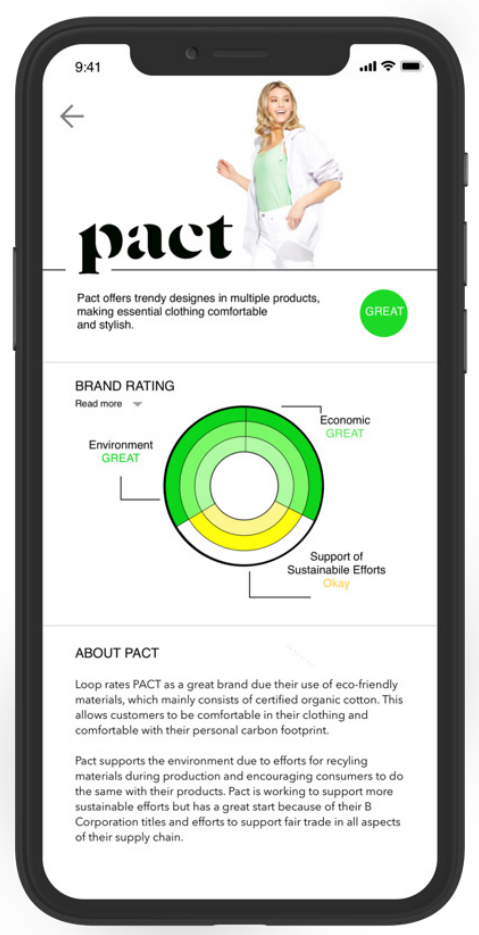


Figure 7: Rating System

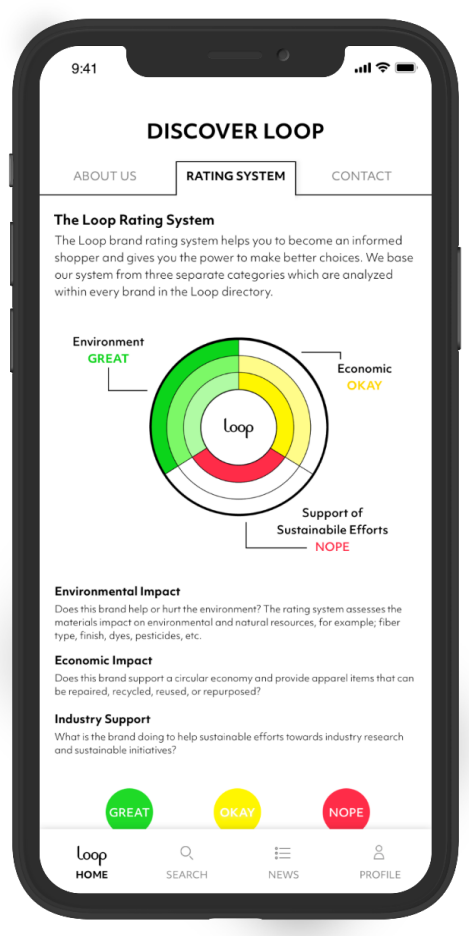

Figure 8: News Search Screen

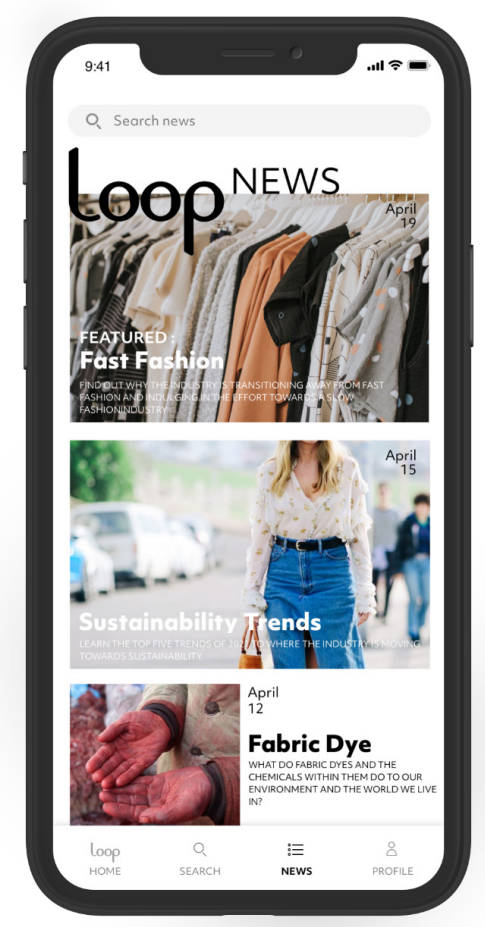

Figure 9: Profile

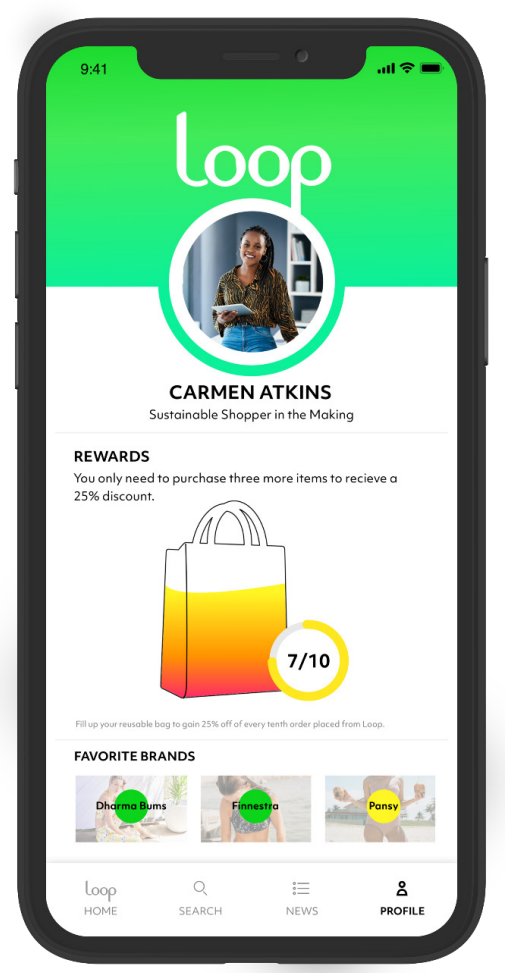




\section{Summary, Conclusion, and Recommendations}

\section{Summary}

The fashion industry impacts all individuals around the world, and sustainable fashion aims to positively influence everyone involved in the apparel industry's supply chain. The fashion industry is focused on strengthening sustainability efforts through leading initiatives. Ultimately, consumers are the priority and their decisions and large purchasing power lead to brand and product success. Product development, supply chain optimization, material utilization, marketing strategy, purchasing patterns, and subsequent repurchasing patterns are driven by the consumer. With further education, consumers can better understand the importance of considering sustainable options when purchasing fashion. Furthermore, it is important for consumers to know that their individual buying choices can have a large collective impact. Positive action through access to information on sustainability will encourage conscious shopping and lead to a prominent change in the apparel industry.

Millennials are the target consumer because they are the largest generation with the most purchasing power. To elicit change, buy-in from Millennials is paramount. Millennials possess an affinity for sustainability and the intent to act, yet they lack the knowledge to do so effectively. Consumers have the power to share their voice through wide-spread digital use, which can lead to influencing the buying habits of other generations. A wealth of information exists in the public sphere via the exhaustive efforts of organizations such as CFDA, SAC, and GFA. However, the dissemination of that information in an easily accessible and digestible format is lacking. Loop will aim to bridge the information gap via an accessible mobile interface that provides the tools to educate conscious consumers and influence sustainable purchases.

\section{Conclusion}

The prototyped development of Loop will provide a platform for users to better distinguish sustainable brands within the industry and lead to conscious purchases. The click-through feature allows users to purchase products through the app platform. Loop will encourage purchases from sustainable brands through its simplicity, research-based brand information, and ability to connect users to brand websites and products. Earned rewards within Loop will encourage consumers to continue researching brands and purchase sustainable items linked within the app.

Loop will become the user's guide for sustainable apparel purchases and provide the necessary brand research that will bridge the consumer gap in a simple, easily consumable output. Loop will become the tool for consumer change by providing an accessible digital resource for Millennials to better understand the need for sustainability within the fashion industry. 


\section{Recommendations}

The following recommendations are necessary before the app can be developed. Further study is needed to enhance the overall sustainable research, mobile application, and user experience within Loop. Sustainable fashion is an extensive subject and ethical sustainability is a prominent topic within this category. Further research is needed to incorporate information regarding ethical sustainability to provide an additional rating for each brand included within the Loop application. Ethical practices will include the brand's status in regard to working conditions, child labor, and fair-trade laws. An additional recommendation for further research is for developers to explore partnerships with industry organizations that certify sustainable processes and practices.

Loop is currently presented as a mobile application prototype. This prototype will expand into full development and result in a functioning application for consumer use. Along with the development of this app, the expansion into additional platforms is necessary for optimal exposure. Millennials are more likely to utilize a digital service if it is accessible on various platforms. Multiple platforms will include expansion into an Android application and website in congruence with the iOS mobile application. Brand consistency throughout all sources will capitalize on the Millennial's gravitation towards familiarity and encourage habitual use of this sustainable database and ecommerce system. 


\section{References}

Baizley, D. (2018, January 10). Sustainability and the consumer 2018. WGSN. https://www.wgsn.com/ insight /\#/search/millennials \%253A\%2520the\%2520mass \%2520e ffect/reports

Cline, E. L. (2012). Overdressed: The shockingly high cost of cheap fashion. Penguin Group.

Consumers agree: It's too hard to be sustainable. (2019, September 24). Genomatica. https: //www. globenewswire.com/news-release /2019/09/24/1919942/0/en/Consumers-Agree-It-s-TooHard-to-be-Sustainable.html

D’Souza, C. (2015, April 21). Marketing challenges for an eco-fashion brand: a case study. Fashion Theory, 19(1), 67-82. https://doi.org/10.2752/175174115X14113933306824

Fast fashion quick to cause environmental havoc. (2018, November 14). University of Queensland. https://sustainability.uq.edu.au/projects/recycling-and-waste-minimisation/fast-fashion-quick-cause-environmental-havoc

Fletcher, Kate. (2007, June 1). Slow fashion. Ecologist: The Journal for the Post-Industrial Age. https: $/ /$ theecologist.org/2007/jun/01/slow-fashion

Millennials: Coming of age. (2020). Goldman Sachs. https://www.goldmansachs.com/insights/archive/millennials/

Hahn-Petersen, L. A. (2018, April 21). Millennials say they care about sustainability. So, why don't they shop this way? Business of Fashion. https:/ / www.businessoffashion.com/articles/sustainability/op-ed-millennials-say-they-care-about-sustainability-so-why-dont-they-dont-shop-this-wayHyass, K. K \& Pedersen, E. R. G. (2019, May 16). Toward circular economy of fashion: Experiences from a brand's product take-back initiative. Journal of Fashion Marketing and Management, 23(3), 345-365. https://doi.org/10.1108/JFMM-04-2018-0059

Joint Economic Committee. (2015, February 6). The economic impact of the fashion industry. https://www.jec.senate.gov/public/index.cfm/democrats/2019/2/the-economic-impact-of-the-fashion-industry Leibowitz, D. (2019, January 14). Guide to sustainable strategies. Council of Fashion Designers of America. https://cfda.com/resources/sustainability-resources 
Leibowitz, D. (2019, January 17). Zeroing in on the right sustainable design strategies. Council of Fashion Designers of America. https://cfda.com/news/zeroing-in-on-the-right-sustainable-design-strategies

Mander, J. and Trifonova, V. (2019) Millennials: Examining the attitudes and digital behaviors of Internet users aged 23-36 [PDF file]. Global Web Index. https://www.globalwebindex.com/reports/millennials

Mason, M. (n.d.) What is sustainability and why is it important? Environmental Science. https://www.environmentalscience.org/sustainability

Morgan, A. (Director). (2015). The true cost [Motion Picture]. United States: Life Is My Movie Entertainment.

Sabell, H. (2016, May 4). How consumers affect supply chain management. The College for Adult Learning: Logistics Management. https://collegeforadultlearning.edu.au/how-consumers-affect-supply-chain-management/

Sariatli, F. (2017, January). Linear economy versus circular economy: A comparative and analyzer study for optimization of economy for sustainability. Visegrad Journal on Bioeconomy and Sustainable Development. 6 (1), 31-34. https://doi.org/10.1515/vjbsd-2017-0005

Stahel, W. R. (Mar 24, 2016). Circular economy: A new relationship with our goods and materials would save resources and energy and create local jobs. Nature, 531, 435-438. https://doi. org $/ 10.1038 / 531435 \mathrm{a}$

Stanley, M. (2017). Sustainable signals: New data from the individual investor. https: //www.morganstanley.com/pub/content/dam/msdotcom/ideas/sustainable-signals/pdf/Sustainable Signals Whitepaper.pdf

Towards a circular economy: Business rationale for an accelerated transition. (2015, November). Ellen MacArthur Foundation. https://www.ellenmacarthurfoundation.org/assets/downloads/ TCE_Ellen-MacArthur-Foundation-9-Dec-2015.pdf

United States Environmental Protection Agency. (2019, November). Advancing sustainable materials management: 2017 fact sheet. https://www.epa.gov/facts-and-figures-about-materials-waste-andrecycling/advancing-sustainable-materials-management 


\section{APPENDIX A}

\section{United Nations 17 Sustainable Development Goals}

Excerpted from: https://www.un.org/development/desa/disabilities/envision2030.html

The 17 sustainable development goals (SDGs) to transform our world:

GOAL 1: No Poverty GOAL 2: Zero Hunger

GOAL 3: Good Health and Well-being GOAL 4: Quality Education

GOAL 5: Gender Equality

GOAL 6: Clean Water and Sanitation GOAL 7: Affordable and Clean Energy

GOAL 8: Decent Work and Economic Growth GOAL 9: Industry, Innovation and Infrastructure

GOAL 10: Reduced Inequality

GOAL 11: Sustainable Cities and Communities GOAL 12: Responsible Consumption and Production GOAL 13: Climate Action

GOAL 14: Life Below Water GOAL 15: Life on Land

GOAL 16: Peace and Justice Strong Institutions GOAL 17: Partnerships to achieve the Goal 